\title{
Functional Overlap Between Murine Inpp5b and Ocrl1 May Explain Why Deficiency of the Murine Ortholog for OCRL1 Does Not Cause Lowe Syndrome in Mice
}

\author{
Pasi A. Jänne, ${ }^{\star}$ Sharon F. Suchy, ${ }^{\ddagger}$ David Bernard, ${ }^{\prime}$ Michael MacDonald, ${ }^{\S}$ Jacqueline Crawley, ${ }^{\S}$ Alexander Grinberg, \\ Anthony Wynshaw-Boris, ${ }^{\ddagger}$ Heiner Westphal, $\|$ and Robert L. Nussbaum ${ }^{\ddagger}$ \\ $*$ Department of Genetics, University of Pennsylvania School of Medicine, Philadelphia, Pennsylvania 19102; ${ }^{\ddagger}$ Laboratory of Genetic \\ Diseases Research, National Human Genome Research Institute, Bethesda, Maryland 20892; ${ }^{\S}$ Experimental Therapeutics Branch,

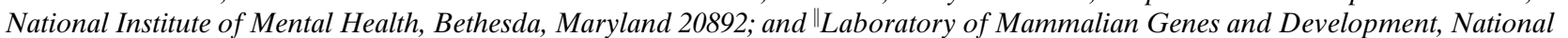 \\ Institute of Child Health and Human Development, Bethesda, Maryland 20892
}

\begin{abstract}
The oculocerebrorenal syndrome of Lowe (OCRL) is an $\mathrm{X}$-linked human genetic disorder characterized by mental retardation, congenital cataracts, and renal tubular dysfunction. The Lowe syndrome gene, OCRL1, encodes a phosphatidylinositol 4,5-bisphosphate 5-phosphatase in the Golgi complex. The pathogenesis of Lowe syndrome due to deficiency of a phosphatidylinositol 4,5-bisphosphate 5-phosphatase in the Golgi complex is unknown. We have used targeted disruption in embryonic stem cells to make mice deficient in Ocrl1, the mouse homologue for OCRL1, as an animal model for the disease. Surprisingly, mice deficient in Ocrl1 do not develop the congenital cataracts, renal Fanconi syndrome, or neurological abnormalities seen in the human disorder. We hypothesized that Ocrl1 deficiency is complemented in mice by inositol polyphosphate 5-phosphatase (Inpp5b), an autosomal gene that encodes a phosphatidylinositol bisphosphate 5-phosphatase highly homologous to Ocrl1. We created mice deficient in Inpp5b; the mice were viable and fertile without phenotype except for testicular degeneration in males beginning after sexual maturation. We crossed mice deficient in Ocrl1 to mice deficient in Inpp5b. No liveborn mice or embryos lacking both enzymes were found, demonstrating that Ocrl1 and Inpp5b have overlapping functions in mice and suggesting that the lack of phenotype in Ocrl1-deficient mice may be due to compensating Inpp5b function. (J. Clin. Invest. 1998. 101: 2042-2053.) Key words: mouse - mutant strain • phosphoinositides • Fanconi syndrome • cataract
\end{abstract}

\section{Introduction}

The oculocerebrorenal syndrome of Low (OCRL) $)^{1}$ was first described in 1952 (1) in a newborn with aminoaciduria, decreased renal ammonia production, hydrophthalmos, and mental retardation. Descriptions of additional infants with similar features led to the identification of the cardinal fea-

Address correspondence to Dr. Robert L. Nussbaum, Chief, Laboratory of Genetic Diseases Research, Building 49, Room 4A72 NIH, 49 Convent Drive, Bethesda, MD 20892-4472. Phone: 301-402-2039; FAX: 301-402-2170; E-mail: rlnuss@nhgri.nih.gov

Received for publication 6 December 1997 and accepted in revised form 4 March 1998.

The Journal of Clinical Investigation

Volume 101, Number 10, May 1998, 2042-2053

http://www.jci.org tures of the syndrome: congenital cataracts, Fanconi syndrome of the proximal renal tubules, and mental retardation inherited as an X-linked trait (2). OCRL is a rare disease with only a few hundred known patients in the United States (3).

The main ophthalmologic mainfestation of OCRL is congenital cataracts, seen as early as 20-24 wk of gestation, and always present at birth (2). Female carriers of OCRL have no clinical symptoms but do show lens abnormalities in the form of tiny punctate opacities in the cortex visible by slit lamp examination $(4,5)$.

Mental retardation is commonly seen in OCRL patients. Mean IQ is in the moderate range $(40<\mathrm{IQ}<54)$ although $25 \%$ of patients score above and $25 \%$ below this interval (3, 6). Neonatal and infantile hypotonia of central nervous system origin is also a frequent feature but improves or disappears with age (2). Neuropathological examination of OCRL brains has been reported to range from completely normal to variously abnormal, with no specific pathologic findings $(2,3,7)$.

The primary renal manifestations are the Fanconi syndrome of renal tubular acidosis due to bicarbonate wasting, aminoaciduria, and phosphaturia; proteinuria; and a urinary concentrating defect $(2,7)$. Renal dysfunction is not always present at birth and may take several months to develop. The aminoaciduria is generalized, with increased wasting of basic amino acids and cysteine and a relative sparing of the branched chain amino acids. Phosphaturia with increased fractional excretion of phosphate is frequent and may worsen with age leading to rickets and fractures if not treated. Proteinuria of both glomerular and tubular origin is also seen and can be severe enough to cause nephrotic syndrome $\left(>1.0 \mathrm{~g} / \mathrm{m}^{2} / \mathrm{d}\right)$. OCRL patients also have a relative inability to concentrate their urine. Pathologically, the kidneys can appear normal in infants but, by early childhood, atrophy, dilation, and the luminal accumulation of proteinaceous material develops predominately in the proximal tubules but also in Henle's loop and the distal tubules $(2,4)$.

The OCRL1 gene encodes a phosphatidylinositol 4, 5-bisphosphate $\left(\mathrm{PtIns}_{2}\right)$ 5-phosphatase which is deficient in Lowe syndrome patients' fibroblasts $(8,9)$. The protein has been localized predominantly to the Golgi complex by immunohistochemistry and Golgi perturbation assays (10, and Suchy, S.F., and R.L. Nussbaum, unpublished data) but a lysosomal localization has also been suggested (11). How a deficiency in this enzyme leads to the clinical phenotype is completely un-

1. Abbreviations used in this paper: dpc, days after coitum; DT-A, diphtheria toxin A fragment; ES, embryonic stem cells; Inpp5b, inositol polyphosphate 5-phosphatase; OCRL, oculocerebrorenal syndrome of Lowe; PtInsP $\mathrm{P}_{2}$, phosphatidylinositol 4,5-bisphosphate; RT, reverse transcriptase. 
known. As a first step towards understanding the pathogenesis of Lowe syndrome at the cellular and organ level, we attempted to create a mouse model of the disorder by gene targeting in embryonic stem cells (ES) $(12,13)$. Surprisingly, mice with complete deficiency of this enzyme are asymptomatic and show none of the signs of Lowe syndrome. The normal phenotype in Ocrl1-deficient mice may be due to the enzyme activity of inositol polyphosphate 5-phosphatase (Inpp5b), an autosomal homologue of $\mathrm{Ocrl1}$, which we show here must have some functional overlap with $O c r l 1$ because attempts to breed mice deficient in both enzymatic activities led to an early embryonic lethal phenotype.

\section{Methods}

\section{Animal strains, care, and breeding}

C57BL/6, 129/Sv were purchased from Jackson Laboratories (Bar Harbor, ME). NIH Black Swiss were purchased from Taconic (Germantown, NY). All animal experiments were approved by the National Human Genome Research Institute's and National Institute of Mental Health's Animal Care and Use Committees and followed the National Institutes of Health guidelines.

\section{Genomic library screening}

Mouse (129/Sv) genomic phage and cosmid libraries were purchased from Stratagene (La Jolla, CA). The phage library was screened in duplicate with the entire $O C R L 1$ cDNA that had been ${ }^{32} \mathrm{P}$-labeled (GIBCO BRL, Gaithersburg, MD) using Benton-Davis screening procedure on Sure-blot hybridization membranes (Oncor, Gaithersburg, MD) according to the manufacturer's protocols. Genomic DNA was prepared from the positive phage plaques using the $\mathrm{CsCl}$ purification method as described previously (14) except plate lysates were used instead of liquid culture. The cosmid library was screened by colony hybridization according to the manufacturer's instructions. The screening was done with a ${ }^{32} \mathrm{P}$-labeled (Pharmacia, Piscataway, NJ) 1.4-kb fragment of the mouse Inpp5b cDNA (a gift of Dr. Larry Charnas, National Institutes of Health, Bethesda, MD) corresponding to the $3^{\prime}$ end of the gene as probe. Cosmid DNA was prepared by standard protocols (14)

\section{Characterization of genomic clones}

All purified mouse genomic clones were characterized by restriction enzyme digestion using enzymes purchased from Boehringer Mannheim (Indianapolis, IN) or New England Biolabs (Beverly, MA). Southern blotting was done as described (14) onto Zetabind (Cuno Inc., Meriden, CT) or Hybond-N membranes (Amersham, Arlington Heights, IL). Hybridization was carried out at $42^{\circ} \mathrm{C}$ (hybridization buffer: $50 \%$ formamide, $1 \times$ Denhardt's, $1 \%$ SDS, $3 \times$ SSPE) to portions of the $O C R L 1$ cDNA labeled with ${ }^{32} \mathrm{P}$ (GIBCO BRL). The coding region of the OCRL1 cDNA was divided into 10 segments (15) and individual segments were amplified by PCR, labeled with ${ }^{32} \mathrm{P}$, and used as probes. Inpp $5 b$ cDNA was divided in two by an EcoRI restriction site which led to the creation of a more $5^{\prime} \sim 400$-bp piece of coding sequence and a more $3^{\prime} \sim 1$-kb piece containing the $3^{\prime}$ end of the coding sequence and the $3^{\prime}$ untranslated portion of the gene. This allowed the identification of mouse genomic clones that contained $5^{\prime}$, middle, or 3' exons of the Ocrl1 or Inpp5b genes. All Southern blot positive clones were subcloned into either pBluescript or $\mathrm{pGem} 9 \mathrm{z}$ cloning vectors using standard ligation methods (14). Sequencing was done using universal primers (T3, T7, and SP6) using either the sequenase kit (United States Biochemicals, Cleveland, $\mathrm{OH}$ ) or by automated sequencing with fluorescent dideoxy terminators (ABI, Foster City, CA) according to manufacturer's instructions.

\section{RNA analysis}

Northern blotting. Northern blot analysis of mouse brain and kidney RNA used $10 \mu \mathrm{g}$ of total RNA isolated from mice according to pub- lished procedures (14) and probed using a 1.4-kb fragment from the 3 ' end of the coding region of Inpp 5 cDNA. Blots were exposed to $\mathrm{x}$-ray film at $-70^{\circ} \mathrm{C}$ for $24-36 \mathrm{~h}$. Multiple tissue Northern (mouse MTN) blots containing $2 \mu \mathrm{g}$ of polyA ${ }^{+}$mRNA per lane were purchased from Clontech (Palo Alto, CA) and probed using a 1.4-kb fragment of Inpp5b or a 1.7-kb fragment of Ocrl1 cDNA as probes under the manufacturer's suggested conditions and stringency. Northern blot analysis of mouse brain and kidney RNA from Inpp5b-deficient and control mice used $10 \mu \mathrm{g}$ of total RNA according to published procedures (14) using a $1.4 \mathrm{~kb}$-fragment from the $3^{\prime}$ end of the coding region of Inpp 5 cDNA as probe. Blots were exposed to x-ray film at $-70^{\circ} \mathrm{C}$ for $24-36 \mathrm{~h}$. For human expression analyses, both MTN I and II (Clontech) were hybridized to ${ }^{32} \mathrm{P}$ labeled INPP5B cDNA (released by BamHI/Xhol digestion of pBS5P [a gift of Dr. P. Majerus, Washington University, St. Louis, MO] [16]) or human OCRL1 cDNA (17), under the manufacturer's suggested conditions and stringency. Blots were exposed to x-ray film at $-70^{\circ} \mathrm{C}$ for $24-36 \mathrm{~h}$. The $\beta$-actin control was provided by the manufacturer and used per manufacturer's instructions. The $\beta$-actin control blots were exposed to $\mathrm{x}$-ray film for only $15-30 \mathrm{~min}$ at room temperature.

Reverse transcriptase ( $R T)$-PCR. RNA obtained from various mouse embryos was isolated using a $\mathrm{CsCl}$ gradient method (14). RNA from ES and C57BL/6 mouse brain was isolated using the guanidinium isothiocyanate method (RNA-STAT 60; Tel-test B Inc., Friendswood, TX) according to the manufacturer's instructions. Approximately $2 \mu \mathrm{g}$ of total RNA was used in the reverse transcription reaction. For Ocrl1 expression studies, each reaction was carried out using $10 \mathrm{ng}$ of $O c r l 1$ specific primer (5' CCT ACA GTA GAC CCT TTT TGT GTG $3^{\prime}$ ) for $1 \mathrm{~h}$ at $37^{\circ} \mathrm{C}$ under the manufacturer's suggested conditions (GIBCO BRL). Once completed, $3 \mu$ l of this reaction mixture was used in nested $\mathrm{PCR}$ reactions using primers as a forward primer (5' ACC CCT TCA AGT CCC CAA AG $3^{\prime}$ ) and reverse primer ( $5^{\prime}$ TCT TCC TCG TTC CCA AGC AG $\left.3^{\prime}\right)$.

For Inpp5b expression studies, each reaction was carried out using $10 \mathrm{ng}$ of an Inpp $5 b$-specific (5' ATG TCT TCA CAA GTC AGC ATG $3^{\prime}$ ) primer for $1 \mathrm{~h}$ at $37^{\circ} \mathrm{C}$ under the manufacturer's suggested conditions (GIBCO BRL). Once completed, $3 \mu \mathrm{l}$ of this reaction mixture was used in two separate nested standard PCR reactions with primers as follows: forward (5' CCA TAG CTG CTT GGA GTG TTC $3^{\prime}$ ) and reverse (5' TCT AGG CTC AGG TAG AAG AAA CAG $\left.3^{\prime}\right)$. For both genes, the PCR was carried out for 30 cycles with each cycle being: $94^{\circ} \mathrm{C}$ for $1 \mathrm{~min}, 50^{\circ} \mathrm{C}$ for $1 \mathrm{~min}$, and $72^{\circ} \mathrm{C}$ for $1 \mathrm{~min}$. The PCR products were separated on $1.5 \%$ agarose and visualized by ethidium bromide.

Immunoblotting. Western analysis was done on tissues homogenized in a buffer containing 1\% Triton X-100 and on ES lysates made from cells that were grown on gelatin-coated plates for two passages, trypsinized, and lysed in loading buffer. Protein concentration was by Bio-Rad (Hercules, CA) assay according to the manufacturer's instructions. Equal amounts of protein from all tissues and ES were boiled in loading buffer and separated by electrophoresis on a $6 \%$ SDS/acrylamide gel (18). The gel was transferred to a PVDF membrane (United States Biochemicals) and probed with an anti-OCRL1 antibody (10). A horseradish peroxidase-linked goat anti-rabbit antibody was used as the secondary antibody allowing visualization by chemiluminescence (Amersham).

\section{Making of gene targeting vectors for Ocrl1 and Inpp5b}

For Ocrl1, the PGK-neo cassette (19) was obtained from M.A. Rudnicki (Massachusetts Institute of Technology, Cambridge, MA) and the diphtheria toxin A fragment (DT-A) (20) was a gift of Dr. J. McCarrick (Wistar Institute, Philadelphia, PA). All vectors used for cloning were gel purified and alkaline phosphatase-treated (Boehringer Mannheim) if necessary. All PCR reactions were performed in a Perkin-Elmer (Norwalk, CT) thermal cycler in a reaction volume of $50 \mu \mathrm{l}$ unless otherwise indicated. PCR for site-directed mutagenesis by overlap extension was performed essentially as described previously (21). The primers used for the primary PCR were MOS1X2 (5' 
ATA GAT CAC CCA GAG CCA GTC ATC TGT $3^{\prime}$ ) with a universal primer (T3) and MOS2V (5' TGG CTC TGG GTG ATC TAT TCT AGA AGC $3^{\prime}$ ) with a universal primer (T7) using clone 17A.12. The PCR reaction was done according to the manufacturer's suggested conditions (Perkin-Elmer) with the following PCR conditions: $95^{\circ} \mathrm{C}$ for $1 \mathrm{~min}, 48^{\circ} \mathrm{C}$ for $2 \mathrm{~min}$, and $72^{\circ} \mathrm{C}$ for $3 \mathrm{~min}$ for 30 cycles followed by $72^{\circ} \mathrm{C}$ for $7 \mathrm{~min}$. The two resulting products were then combined in a secondary PCR reaction with primers $\mathrm{T} 7$ and $\mathrm{T} 3$ under the identical PCR conditions as described above. The resulting product was purified as described above and cloned (17A.17).

The primers used to introduce three frame stop codons into Inpp $5 b$ along with an artificial XhoI site for insertion of a neomycin cassette were as follows: forward (5' TAA TTA GCT GAC TCG AG $3^{\prime}$ ) and reverse (5' CTC GAG TCA GCT AAT TA 3'). The two oligonucleotides (100 ng of each) were annealed to each other in a $50-\mu \mathrm{l}$ reaction in $50 \mathrm{mM} \mathrm{NaCl}$ and $10 \mathrm{mM}$ Tris $\cdot \mathrm{Cl}, \mathrm{pH}$ 7.5. $2 \mu \mathrm{l}$ of this mixture was used in a standard ligation reaction into a unique StuI restriction site located within an exon of the Inpp $5 b$ gene and the orientation verified by acrylamide gel electrophoresis. The rest of the targeting vector construction used standard cloning techniques.

\section{Growth and maintenance of ES and feeder cells}

CCE ES and SLN2 feeder cells were a gift from Dr. E. Robertson (Harvard University, Cambridge, MA) (22). J1 ES were obtained from Dr. R. Jaenisch (Massachusetts Institute of Technology, Cambridge, MA) (23). TC1 ES (24) were grown and maintained at the transgenic animal facility of the National Human Genome Research Institute (Bethesda, MD). Cells were electroporated and transformants resistant to genticin were picked, expanded, and tested by Southern blotting for homologous C57BL/6 blastocysts essentially as described previously (22).

Chimeric male mice were bred to C57BL/6 or NIH Black Swiss females starting at the age of $6 \mathrm{wk}$. The offspring were scored for the presence of agouti coat color indicating germ line transmission of the recombined allele and confirmed by Southern blot analysis of DNA from tail samples (19).

\section{Characterization of $\mathrm{Ocrl}^{-}$and Inpp5b ${ }^{-/-}$mice}

Histological analyses. Histological sections, staining, and pathological examination were performed in the transgenic pathology laboratory at University of California, Davis, or in the Veterinary Pathology Service at the National Institutes of Health. All tissues were dissected from normal and mutant mice and preserved in $10 \%$ formalin for 24 $48 \mathrm{~h}$. They were then transferred to $70 \%$ ethanol for sectioning and staining with hematoxylin and eosin.

PtIns $P_{2}$ 5-phosphatase assay. Enzyme assays for PtIns $\mathrm{P}_{2}$ 5-phosphatase were performed in duplicate as described previously (8) except that assays were performed with the ratio of cetylammonium bromide detergent to substrate in the reaction mixture set at either 10:1 or 2.5:1. Assays were performed on cultured mouse embryonic fibroblasts from normal, $\mathrm{Ocrl1}^{-}$, and Inpp5 $\mathrm{b}^{-}$mice isolated from 13.5 days after coitum (dpc) embryos by published methods (19).

Urine analysis. Urine was collected from mice for a period of $24 \mathrm{~h}$ in metabolic cages. The samples were frozen at $-70^{\circ} \mathrm{C}$ until they were used. The quantitative amino acid analyses were performed in the metabolism laboratory at the Children's Hospital of Philadelphia. Total creatinine was measured in the samples and the amino acids were separated by HPLC. The reported amino acid concentrations were then calculated as $\mathrm{mmol} / \mathrm{mg}$ creatinine. Urine glucose and total protein analysis was done using standard urine dipsticks (ChemStrip; Boehringer Mannheim) on the same samples that were analyzed for amino acids.

Serum chemistry analyses. Normal, $\mathrm{Ocrl}^{-}$, and Inpp5b mice were anaesthetized (using 1:1 mixture of 10\% ketamine xylezine) and blood was obtained through a retroorbital bleed. The serum was separated and analyzed by an Ektachem DT-60 analyzer (Eastman Kodak, Rochester, NY). Urine and serum creatinine were analyzed using the single slide method. For analysis of urine creatinine and phosphorus, the samples were first diluted 1:20 in water before analysis.
Behavioral analyses. $\mathrm{Ocrl}^{-}$mice $\sim 4-5$ mo old were tested as described previously (25). Behavioral data were analyzed for statistical significance between genotypes using one-way (ANOVA) followed by Sheffe's post-hoc analysis.

Rotorod. The ability to maintain balance on a $10.0-\mathrm{cm}$-diameter rotating cylinder was measured with a standard rotorod apparatus at $6.67 \mathrm{rpm}$. Latency to fall off the rotating cylinder was measured. Mice that fell in $<10 \mathrm{~s}$ were given a second trial. Mice that did not fall during the $60 \mathrm{~s}$ trial period were removed and given a score of $60 \mathrm{~s}$.

Open field behavior. Exploratory locomotor activity was measured in an open field measuring $45 \times 45 \mathrm{~cm}$, over a 5 -min period. A Digiscan apparatus (model RXYZCM [8]; Omnitech Electronics, Columbus, $\mathrm{OH}$ ) automatically recorded and analyzed the behavioral parameters. The apparatus had eight photocells in each horizontal direction. Movements were categorized by the number, timing, and pattern of photocell beam breaks. Horizontal activity comprised the total number of photocell beam breaks in the horizontal plane during the 5-min testing session.

Passive avoidance. Passive avoidance was tested in a $40.0 \times 16.25 \times$ 20.0-cm shuttle box (ENV-010M; Med Associates, Fairfield, VT). A wall with a sliding door separated the shuttle box into two equal-sized compartments, each $20 \mathrm{~cm}$ long. One of the compartments was darkened using black construction paper taped to the outside wall; the other compartment was illuminated by the fluorescent light bulbs on the ceiling, $\sim 1.5 \mathrm{~m}$ above the shuttle box. The floor of the shuttle box was comprised of stainless steel bars, $0.4 \mathrm{~cm}$ in diameter and 1.0 $\mathrm{cm}$ apart. The floor of the dark compartment was wired to a shock generator (Lafayette Instrument Co., Lafayette, IN), set to deliver a $0.3-\mathrm{mA}, 110-\mathrm{V}$ foot shock. The sliding door was controlled by the experimenter to allow or prevent access from one compartment to the other. On the first day, mice were put in the lighted compartment with the sliding door closed. $10 \mathrm{~s}$ later, the sliding door was opened. Upon entering the dark compartment, the sliding door was closed and a $2 \mathrm{~s}$ foot shock was delivered through the grid floor. The mouse remained in the dark compartment for 10s and then was returned to its home cage. Retention was tested $24 \mathrm{~h}$ later using an identical procedure. Latency to enter the dark compartment was the primary dependent measure, and was taken as an index of the animal's memory of the previous day's aversive experience. The procedure was repeated at 24-h intervals, until the mouse stayed in the lighted compartment for $300 \mathrm{~s}$. An increase in latency to enter the dark compartment over successive test sessions indicates improvement in remembering the association between the dark compartment and prior foot shock.

\section{Characterization of double mutant mice}

Mice heterozygous for mutations in Ocrl1 and Inpp $5 b$ were intercrossed so that either 1 in 4 or 1 in 8 offspring would be expected to be Inpp $5 b^{-1-} \mathrm{Ocrl1}^{-1 y}$ or Inpp $5 b^{-1-} \mathrm{Ocrl1}^{-1-}$. Liveborn mice and mouse embryos at $9.5 \mathrm{dpc}$ were genotyped at their Ocrl1 and Inpp5b loci. When embryos were analyzed, the uteri were examined for resorptions.

\section{Results}

We have demonstrated previously by Northern analysis that human OCRL1 is widely expressed, with the highest levels seen in brain, liver, and kidney (10). Expression of murine Ocrl1 is similar to what is seen for human OCRL1 in most tissues except for the testis where the relative expression is quite high in humans but significantly lower in mice (Fig. $1 a$ ). Murine Ocrl1 is also expressed in ES and in developing mouse embryos at all stages tested, from days 9.5 to 16.5 after coitum as determined by RT-PCR (Fig. $1 b$ ). Although the timing and pattern of expression of $O C R L 1$ in human embryonic tissues are for the most part uncharacterized, the congenital nature of the ophthalmologic and neurological components of the phe- 
a.

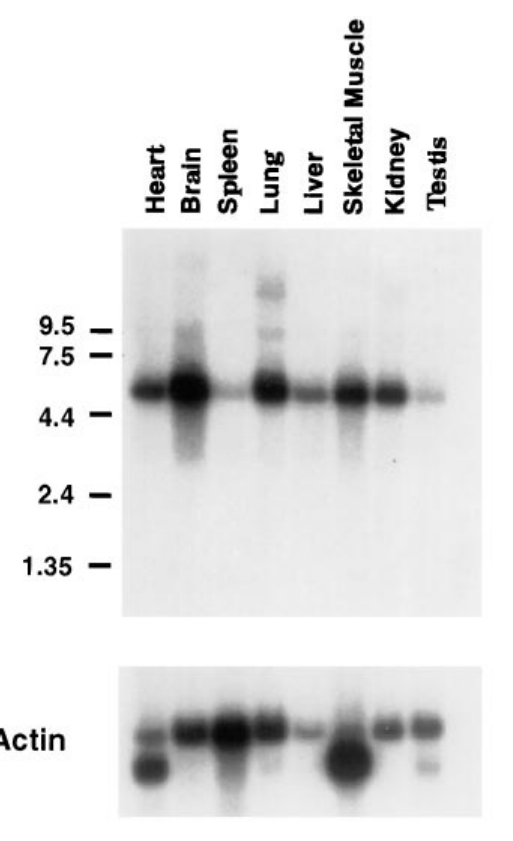

b.

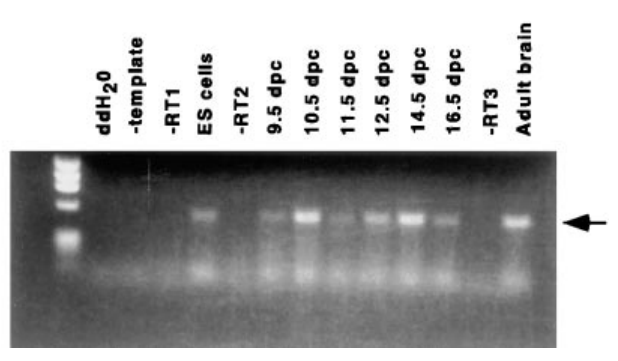

Figure 1. (a) Expression of $O c r l 1$ in various adult mouse tissues. The entire Ocrll cDNA was hybridized to a Northern blot containing $2 \mathrm{mg}$ of poly $\mathrm{A}^{+}$mRNA (Clontech) from each of the organs listed above. The blot was hybridized using the manufacturer's suggested conditions, washed to high stringency, and exposed to x-ray film at $-70^{\circ} \mathrm{C}$ for $24 \mathrm{~h}$. The blot was then stripped and hybridized with a $\beta$-actin cDNA. The blot was then exposed to x-ray film at $-70^{\circ} \mathrm{C}$ for $15 \mathrm{~min}$. (b) RT-PCR analysis of Ocrl1 expression in ES and developing mouse embryos. Approximately $1 \mu \mathrm{g}$ of total RNA was reverse transcribed and then subjected to a nested PCR using Ocrll specific primers. The products were then separated on a $1.3 \%$ agarose gel, stained with ethidium bromide, and photographed.

notype and the presence of enzyme in chorionic villus samples and amniotic fibroblasts (26) suggest that $O C R L 1$ expression is important during human embryonic development. Thus, the gene is expressed in adult mouse tissues in a pattern similar to that seen in adult humans, and is expressed in mice during embryonic development.

Screening $6 \times 10^{6}$ clones of a murine $129 / \mathrm{Sv}$ genomic phage library $(2.5 \times$ coverage of the murine genome $)$ using the entire human OCRL1 gene as a probe yielded five positive clones covering the entire gene (data not shown). An $\sim 10$-kb EcoRI fragment from phage contained six exons (data not shown) corresponding to exons $18 \mathrm{~A}$ to 23 of the human OCRL1 gene (27). Five of these exons were sequenced from mouse genomic DNA and the exon/intron boundaries were found to be identical (data not shown) to the human exon/intron boundaries (27).

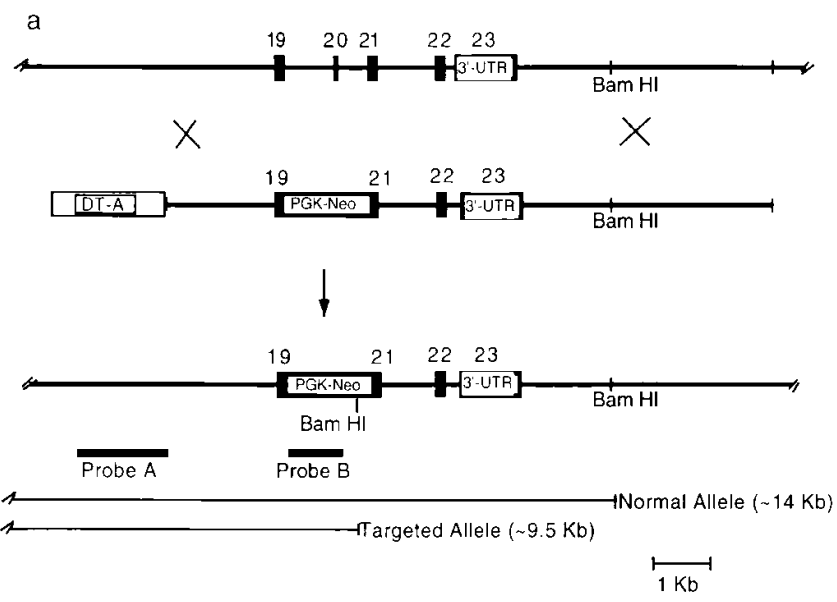

b

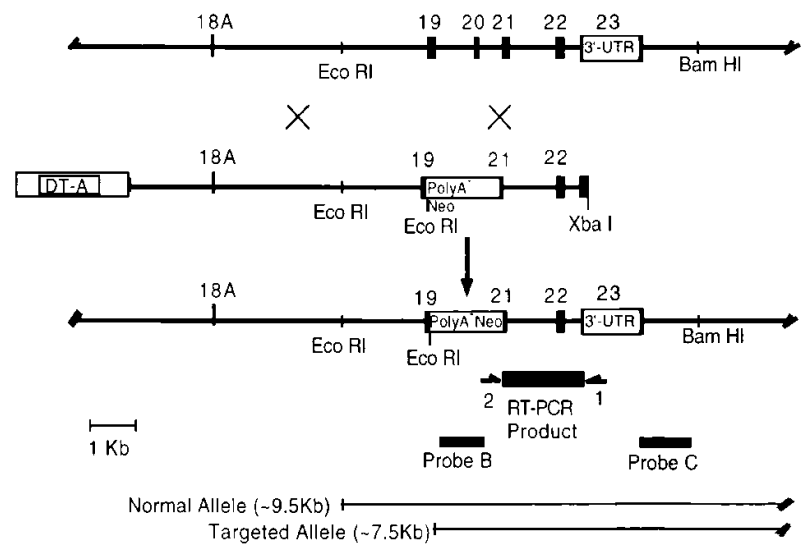

Figure 2. (a) Gene targeting at the Ocrl1 locus. Gene targeting was performed near the $3^{\prime}$-end of the Ocrl1 locus. This gene targeting vector $\left(\mathrm{pOcrl1}{ }^{\text {neo }}\right)$ is a classical positive-negative type vector. There is $\sim 2 \mathrm{~kb}$ of homology $5^{\prime}$ to the neomycin resistance cassette and $6.5 \mathrm{~kb}$ of homology $3^{\prime}$. Homologous recombination is detected by restriction enzyme digestion using BamHI followed by Southern blotting and hybridization with probe $\mathrm{A}$ (derived from a region $5^{\prime}$ to the targeting vector). The endogenous allele detected by probe $\mathrm{A}$ is $\sim 14.0 \mathrm{~kb}$ and the recombinant allele is $9.5 \mathrm{~kb}$. (b) Gene targeting at the $O c r l 1$ locus using a polyadenylation trap. The polyA ${ }^{-}$neo gene targeting vector ( $\mathrm{pOcrl1^{ \text {polyA-} }}{ }^{-}$) is shown. This vector contains $\sim 4.5 \mathrm{~kb}$ of homology $5^{\prime}$ to the neo gene and $2 \mathrm{~kb}$ of homology $3^{\prime}$. This vector does not contain a $3^{\prime}$ UTR. Homologous recombination is detected by restriction enzyme digestion using EcoRI followed by Southern blotting and hybridization with probe $\mathrm{C}$ (which contains the 3' UTR of $O$ crl1). The endogenous allele is $\sim 9.5 \mathrm{~kb}$ and the recombinant allele is $\sim 7.5 \mathrm{~kb}$ Alternatively, the recombination event can be detected using RTPCR using an RT primer derived from the $3^{\prime}$ UTR and PCR primers derived from neo and the $3^{\prime}$ UTR. This reaction amplifies the chimeric transcript made as a result of the homologous recombination event.

The gene targeting strategy at the Ocrll locus was modeled after patient mutations in which premature terminations near the $3^{\prime}$-end of the gene caused Lowe syndrome clinically indistinguishable from patients who made no OCRL1 mRNA (15, 28). A gene targeting event that truncated the protein near this region was judged sufficient to completely disrupt the function of the Ocrll gene. 
Two gene targeting vectors were made for Ocrll from the $3^{\prime}$ end of the gene. The site directed mutagenesis by overlapping extension method (23) was used to delete all of exon 20 and half of exons 19 and 21 and fuse exons 19 and 21 at an artificial, unique BglII restriction site engineered to have an inframe stop codon in exon 19. For one vector $\left(\mathrm{pOcrl1}{ }^{\text {neo }}\right)$, a complete PGK-neo cassette was cloned into the artificial BglII site with PGK-neo transcribed in the same orientation as Ocrl1. Southern blot analysis of ES genomic DNA digested with BamHI would detect either an $\sim 14$-kb endogenous allele or an $\sim 9.5$-kb targeted allele using a 1.5-kb EcoRI fragment derived from a region outside the targeting construct. DT-A was cloned in as a negative selection marker against nonhomologous recombination (Fig. $2 a$ ).

A second targeting vector ( $\mathrm{pOcrl1}{ }^{\text {polyA-}}$ ) was made in a similar manner except that exon 23 , which contains the $3^{\prime}$ untranslated region of the OCRL1 gene, was removed and a truncated PGK-neo cassette lacking its polyadenylation sequence was inserted to serve as a polyadenylation trap (29). Southern blot analysis of ES DNA digested with EcoRI produces a 9.5-kb endogenous fragment or a 7.5-kb targeted fragment when probed with a $2.5-\mathrm{kb}$ XbaI fragment from outside the region of homologous recombination (Fig. $2 b$ ).

After electroporation of $\mathrm{pOcrl1}{ }^{\mathrm{Neo}}$ into CCE ES, 500 genticin resistant colonies were picked yielding a total of six correctly targeted colonies as determined by Southern blot analysis (data not shown). With construct pOcrl1 ${ }^{\text {polyA- }}, 9$ out of 150 neomycin resistant J1 ES were correctly targeted (data not shown).

After injection of ES into blastocysts, two of the six correctly targeted CCE ES clones were used to generate three and six male chimeras, respectively. After numerous matings, one of the CCE ES derived chimeric mice gave rise to two offspring carrying the knockout allele $\left(O c r l 1^{\text {neo }}\right)$ at a low frequency of $<1 \%$ of all pups. One of these mice, an obligate heterozygous female, was used to establish the colony from the CCE ES. Two J1 cells with correctly targeted $\mathrm{pO}$ crll $1^{\text {polyA- }}$ were used to create chimeric males. The daughter of one of them was used to establish the colony carrying the $O \mathrm{crll}^{\text {polyA-}}$ allele derived from the J1 ES line parent. With germline transmission obtained from two of the targeted cell lines, one from the CCE cells carrying the $O c r l 1^{\text {neo }}$ allele and the other from J1 ES carrying the $O c r l 1^{\text {polyA- }}$ allele, two independently derived lines of mice were developed and were used to verify results obtained from the other.

An RNase protection assay performed using total RNA isolated from brain and kidney of normal and Ocrll ${ }^{\text {neo }}$ male mice revealed a protected fragment in normal mice that was absent in the $\mathrm{Ocrl1}{ }^{\text {neo }}$ males (27). Similarly, Western analysis of organs from $\mathrm{Ocrll}^{\text {polyA- }}$ mice showed no Ocrll protein in the targeted ES or the organs (Fig. 3) whereas it was clearly present in $\mathrm{Ocrll}^{+}$littermates. Thus, both targeted disruptions resulted in loss of Ocrl1 mRNA and protein suggesting that transcript and protein were either not produced or were highly unstable and rapidly degraded.

PtIns $\mathrm{P}_{2}$ 5-phosphatase assays were performed on homogenates of fibroblasts from male mice hemizygous for the Ocrll ${ }^{\text {neo }}$ allele and their normal littermate controls under the same conditions as used previously in Lowe syndrome patients' fibroblasts $(8,28)$. Enzyme activity in mice carrying either the $O c r l 1^{\text {neo }}$ or the $O c r l 1^{\text {polyA- }}$ allele was $0.5 \mathrm{nmol} / \mathrm{min} / \mathrm{mg}$ in fibroblasts, as compared to $4.8 \mathrm{nmol} / \mathrm{min} / \mathrm{mg}$ in fibroblasts of

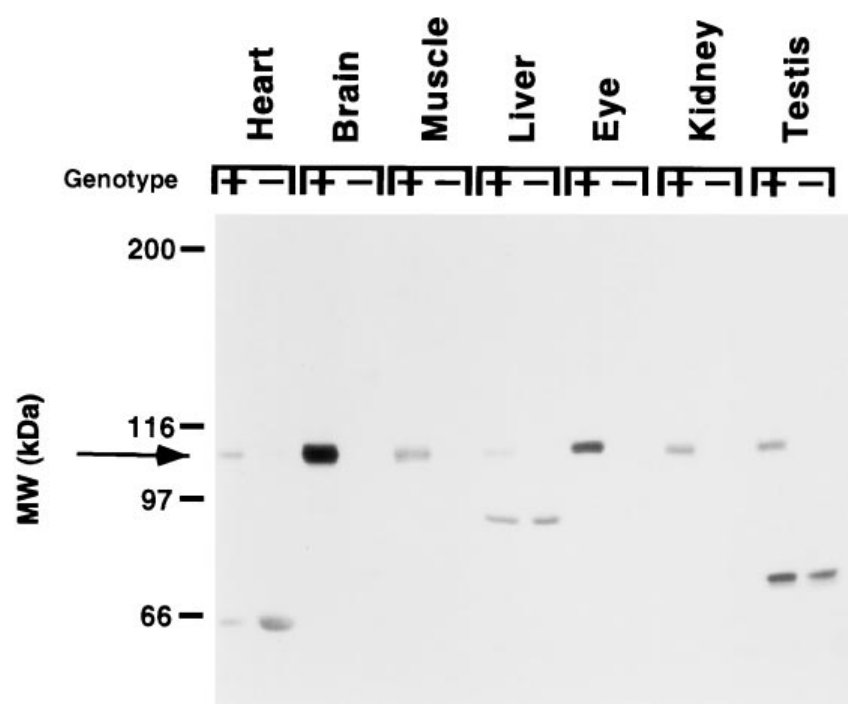

Figure 3. Western analysis of organs from $\mathrm{Ocrl}^{-}$and $\mathrm{Ocrl}^{+}$mice. Equal amounts of protein were boiled in loading buffer and loaded on an SDS/acrylamide gel. The gel was transferred onto PVDF membranes and probed with antibody made against a fusion protein derived from the amino terminus of the mature $O C R L 1$ protein and excluded the region used in the gene targeting experiments (10). Arrow indicates the position of the normal Ocrll protein at $105 \mathrm{kD}$.

normal male mice. These results indicate that the level of $\mathrm{PtInsP}_{2}$ 5-phosphatase activity is comparable in mice and humans and the residual activity in fibroblasts from mice carrying the $O \mathrm{crll}{ }^{\text {neo }}$ allele $(0.5 \mathrm{nmol} / \mathrm{min} / \mathrm{mg})$ is similar to that seen in Lowe syndrome patients' fibroblasts $(0.55 \pm 0.29 \mathrm{nmol} / \mathrm{min} / \mathrm{mg})$ $(28,30)$.

Having established that we had generated a mouse that was genetically and biochemically similar to humans with Lowe syndrome, we proceeded to evaluate the phenotype of these mice. Segregation of the $\mathrm{Ocrll}^{\text {neo }}$ allele was studied in 190 offspring and demonstrated $53 \%$ female and $47 \%$ male, of which $53 \%$ were $\mathrm{Ocrll}^{+}$and $47 \%$ were $\mathrm{Ocrll}^{\text {neo }}$, which conformed to classical Mendelian segregation $(P>>0.05)$. Similar results were obtained with the $O c r l 1^{\text {polyA-}}$ allele. Thus, segregation analysis indicated no prenatal mortality in mice deficient in Ocrll. Humans with Lowe syndrome are severely hypotonic and feed poorly in the early neonatal period. Mice, on the other hand, showed no evidence of perinatal morbidity or lethality of males hemizygous for either knockout allele. There was no difference in the mean weights of $21 \mathrm{Ocrll}^{\text {neo }}$ and Ocrl1 ${ }^{\text {polyA-}}$ male hemizygote mice $(30 \mathrm{~g})$ compared to normal littermates $(31 \mathrm{~g})$ at 4 mo of age. Development and male fertility were normal. Similarly, female mice homozygous for the knockout alleles could be readily generated from crosses between hemizygous males and heterozygous females at normal Mendelian ratios and demonstrated normal growth, development, and fertility.

Mice deficient in $O c r l 1$ protein had no congenital cataract, which is one of the earliest and most reproducible components of the Lowe syndrome phenotype. Follow-up for as long as $1 \mathrm{yr}$ showed normally transparent lenses in the knockout mice. Histological analyses performed on brain, eyes, heart, lung, liver, thymus, salivary gland, spleen, kidney, stomach, small intes- 


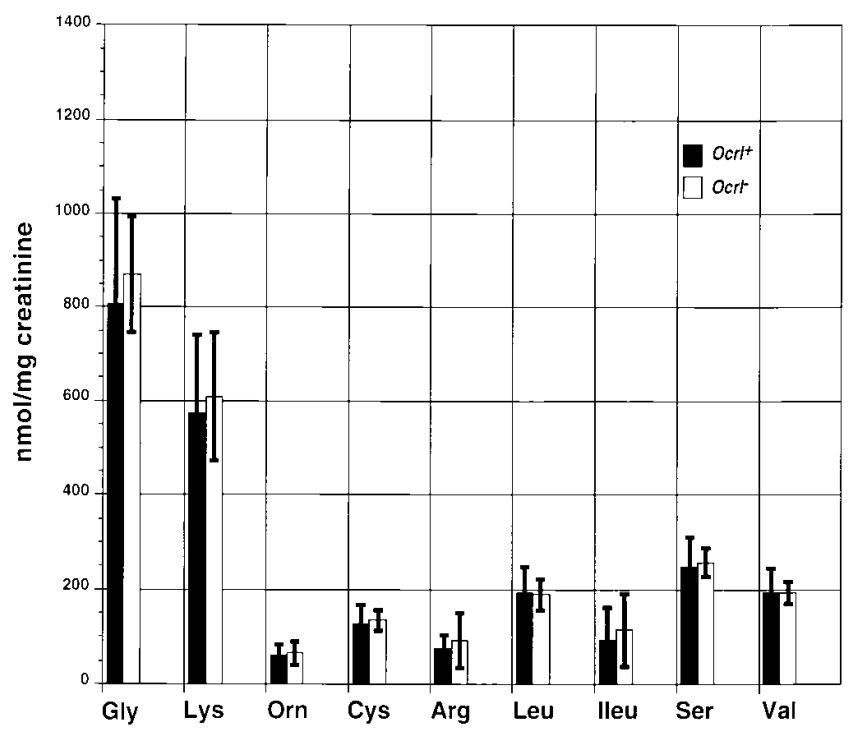

Figure 4. Quantitative urine amino acid analysis. 24-h urine collections were made from male $\mathrm{Ocrl}^{-}$and $\mathrm{Ocrl}^{+}$littermates under a normal mouse diet. Total creatinine in each specimen was measured to normalize amino acid concentrations to creatinine. Each bar represents the mean value for a particular group. Error bars show 1 SD in each direction.

tine, large intestine, testis, skeletal muscle, ovary, and uterus derived from normal and $O$ crll-deficient mice at $\sim 6 \mathrm{wk}$ and again at $1 \mathrm{yr}$ revealed no consistent differences in any of the organs examined.

To evaluate whether $\mathrm{Ocrll}^{-}$mice exhibited signs of Fanconi syndrome, serum and urine chemistries were performed. Serum chemistries were normal in both control and $O c r l 1^{\text {neo }}$ mice without any evidence for metabolic acidosis (data not shown). Simultaneous serum and urine ( $24 \mathrm{~h})$ collections from six $O c r l 1^{\text {neo }}$ (14 separate collections) and five normal mice (10 separate collections) were used to calculate urine amino acid excretion and phosphate clearances. The mean serum phosphate was $6.2 \pm 0.84 \mathrm{mg} / \mathrm{dl}$ (mean $\pm \mathrm{SD}$ ) in the normal mice and $6.4 \pm 1.21 \mathrm{mg} / \mathrm{dl}$ in the $O c r l 1^{\text {polyA- }}$ mice $(P>0.2)$; similarly, there was no difference between the fractional excretion of phosphate in the normals $(13 \%)$ and in the Ocrl1 ${ }^{\text {polyA- }}$ mice $(15 \%)$. No differences were seen in the urine amino acid concentrations in $\mathrm{Ocrll}^{\text {neo }}$ mice compared with normal controls (Fig. 4). Neither group of mice exhibited proteinuria as determined by urine dipstick analyses (data not shown).

As a screening method for assessing neurological function in $\mathrm{Ocrll}^{-}$mice, we tested normal and $\mathrm{Ocrll}^{\text {neo }}$ mice for a demonstrable abnormality in balance, strength, learning, and memory (25). Open field distance and passive avoidance tests were normal, but a borderline-significant difference was seen in the mean length of time mice could remain on a rotorod (Fig. 5). The mean \pm SEM was $50 \mathrm{~s} \pm 4$ for $21 \mathrm{Ocrll}^{+}$and $35 \mathrm{~s}$ $\pm 5 \mathrm{~s}$ for $21 \mathrm{Ocr}^{\text {neo }}$ mice $(P<0.05)$ although there was a high degree of overlap between the normal and $\mathrm{Ocrl1}^{-}$mice.

The fact that $O c r l 1$-deficient mice showed none of the signs of Lowe syndrome suggested that either Ocrl1 does not play the same role in phosphoinositide metabolism in mice as OCRL1 does in humans or that another enzyme might be compensating in mice for loss of Ocrll function. One possible candidate for such a hypothetical compensating activity is Inpp $5 b$ because human INPP5B protein is very similar to the $O C R L 1$ protein and both enzymes have inositol polyphosphate and $\mathrm{PtInsP}_{2}$ 5-phosphatase activities (9). Interestingly, and in contrast to the results found with human $O C R L 1$ and murine $O c r l 1$, Northern blot analysis of INPP5B expression in human tissues and Inpp5b in mouse tissues revealed a significant difference in expression, particularly in tissues affected in Lowe syndrome, such as brain and kidney. As shown in Fig. 6, expression of INPP5B can be seen in 16 of 16 human tissues examined. Two mRNA species are detected that migrate at $\sim 5.2$ and $4.4 \mathrm{~kb}$ (lines). As can be seen, both mRNA species are not found in all of the tissues and the relative levels of the two species varies from tissue to tissue. Both species are de- a.

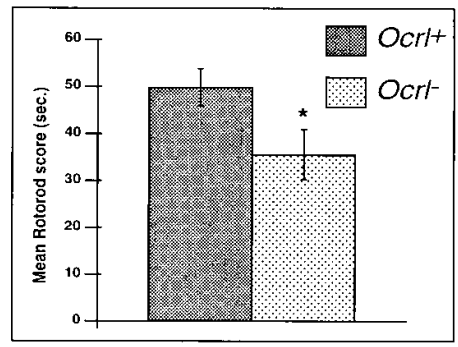

Rotorod Performance

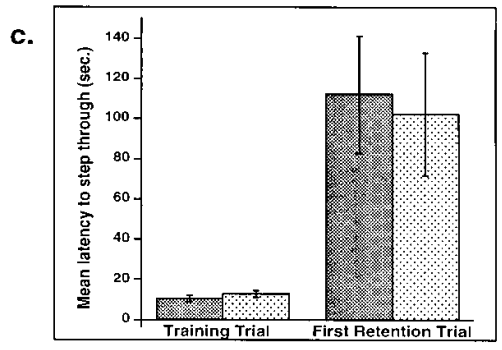

Passive Avoidance Latencies b.

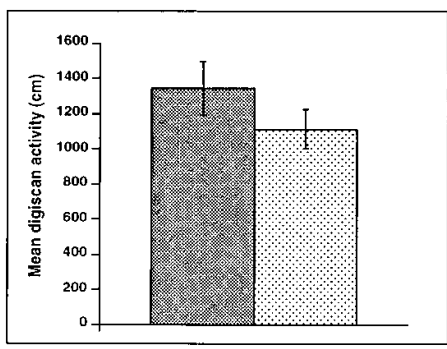

Open Field Distance Travelled

d.

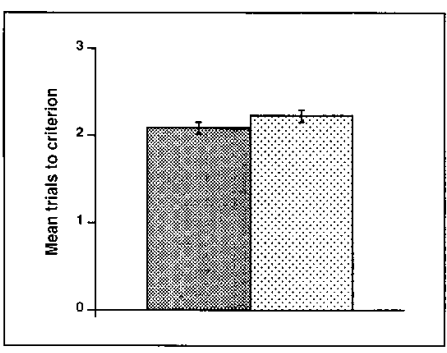

Passive Avoidance Trials to Criterion
Figure 5. Summary of behavioral analyses of $\mathrm{Ocrl}^{-}$ mice. Rotorod performance, a measure of motor coordination, was partially reduced in some $\mathrm{Ocrl}^{-}$mice. Open field locomotor activity and performance on the passive avoidance memory task were not significantly different between genotypes. Data are presented as mean \pm SEM. $n=21$ of each genotype. 


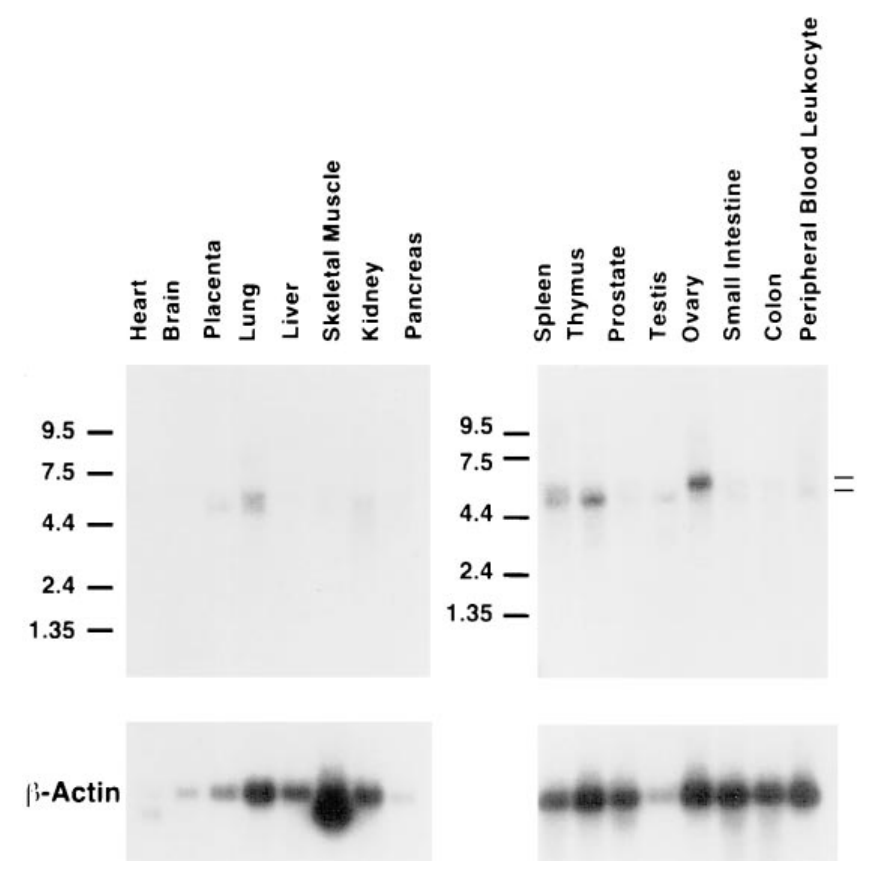

Figure 6. Human INPP5B Northern blot analysis. A multiple tissue Northern blot containing $2 \mu \mathrm{g}$ of human poly $\mathrm{A}^{+}$mRNA (Clontech) was hybridized with human INPP5B cDNA. Exposure time was $24 \mathrm{~h}$ at $-70^{\circ} \mathrm{C}$ with an intensifying screen. The same blot was stripped of signal, hybridized with cDNA for $\beta$-actin, and exposed for $15 \mathrm{~min}$ at $-70^{\circ} \mathrm{C}$ with an intensifying screen.

tected in brain, placenta, lung, spleen, prostate, small intestine, and colon. The 4.4-kb mRNA is the sole species detected in testis and peripheral blood leukocytes. $\beta$-actin was used as a loading control and when normalized to this mRNA, the tissues exhibiting the highest relative level of INPP5B expression are lung, ovary, spleen, and thymus.

The expression of the murine ortholog Inpp5b is seen in all eight tissues examined. Again two mRNA species are detected, migrating at $\sim 4.0$ and $\sim 3.0 \mathrm{~kb}$, respectively. Both mRNA species are detected in all tissues except testis where only the 3.0-kb mRNA is seen (Fig. $7 a$ ). Just as with the human homologue, the relative ratio of the two mRNAs varies in the tissues examined. In brain, the 4-kb mRNA is seen at a much higher level than the 3.0-kb mRNA whereas the opposite is true in spleen. $\beta$-actin was again used for a loading control and when Inpp5b expression is normalized relative to $\beta$-actin, the tissues with the highest level of Inpp $5 b$ expression are kidney, liver, and lung. However, the strength of Northern blot signal for INPP5B in humans appeared significantly reduced as compared to Inpp $5 b$ in mouse. Thus, although human OCRL1 and murine Ocrl1 seem to have similar expression levels and patterns, the difference in steady-state mRNA levels between human INPP5B and murine Inpp5b suggested that one explanation for the difference in phenotype between Lowe syndrome patients and Ocrll-deficient mice was that Inpp5b could compensate for Ocrll deficiency in mice. As shown in Fig. $7 b$, expression of murine Inpp $5 b$ was detected by RT-PCR in ES and in all embryos tested, ranging in age from 9.5 to $16.5 \mathrm{dpc}$.

As a direct test of whether Inpp5b and Ocrll might have

overlapping function in mice, we created a mouse with disruption of Inpp5b to breed them to Ocrl1-deficient mice and generate mice deficient in both enzymatic activities. Screening of $2.4 \times 10^{5}$ colonies from the $129 / \mathrm{Sv}$ mouse cosmid library yielded eight identical positive clones through tertiary screening (data not shown). One of these clones, cMI5P, was used for the remainder of the studies.

A partial genomic structure of Inpp $5 b$ was determined by probing cMI5P with the $1.4-\mathrm{kb}$ partial Inpp $5 b$ cDNA and sequencing subcloned restriction fragments. Cosmid cMI5P was found to contain 11 exons spread out over a physical distance of $\sim 15 \mathrm{~kb}$. A comparison of intron/exon boundaries and the exons of the homologous portions of the human OCRL1 gene revealed substantial conservation of exon size. To construct the targeting vector, a StuI site in the exon of Inpp5b corresponding to exon 13 of $O C R L 1$ was used to introduce a 17-bp oligonucleotide containing stop codons in all three frames followed by a XhoI restriction enzyme site (Fig. 8). This XhoI site was then used to introduce a truncated PGK-neo cassette lacking its polyadenylation sequence to serve as a polyadenylation trap (29) (in the same transcriptional orientation as Inpp5b). The negative selectable marker DT-A was cloned at one end to create the $p$ Inpp $5 b^{\text {polyA- }}$ targeting vector (Fig. 8).

DNA digested with $\mathrm{XbaI}$ and probed using a fragment derived from outside the targeting construct (probe I) detected the endogenous allele of $\sim 5 \mathrm{~kb}$ or the recombinant allele of $\sim 6.4 \mathrm{~kb}$ in the event of homologous recombination (Fig. 8). Gene targeting vector $p$ Inpp $5 b^{\text {polyA- }}$ was electroporated into TC-1 ES. One clone of 40 analyzed was correctly targeted as judged by Southern analysis using a fragment derived from outside the targeting construct as probe. This clone was used to generate several chimeric mice with high coat color contribution which, in turn, produced germline offspring verified by Southern blotting to carry a targeted Inpp5b allele (data not

a.

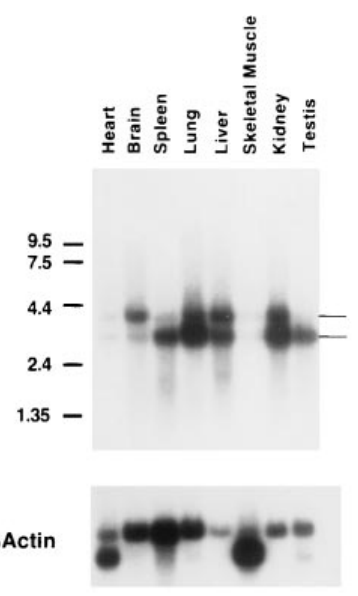

b.

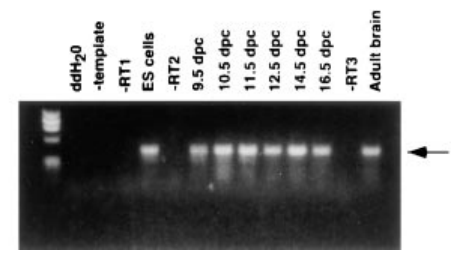

Figure 7. (a) Murine Inpp $5 b$ Northern blot analysis. A multiple tissue Northern blot containing $2 \mu \mathrm{g}$ of murine polyA ${ }^{+}$mRNA (Clontech) was hybridized with mouse Inpp $5 b$ cDNA. Exposure time was $24 \mathrm{~h}$ at $-70^{\circ} \mathrm{C}$ with an intensifying screen. The same blot was stripped of signal, hybridized with cDNA for $\beta$-actin, and exposed for $15 \mathrm{~min}$ at $-70^{\circ} \mathrm{C}$ with an intensifying screen. (b) RT-PCR analysis of Inpp $5 b$ expression in ES and developing mouse embryos. Total RNA $(1 \mu \mathrm{g})$ was reverse transcribed and subjected to nested PCR with

Inpp 5 -specific primers. Products were separated on $1.3 \%$ agarose, stained with ethidium bromide, and photographed. 

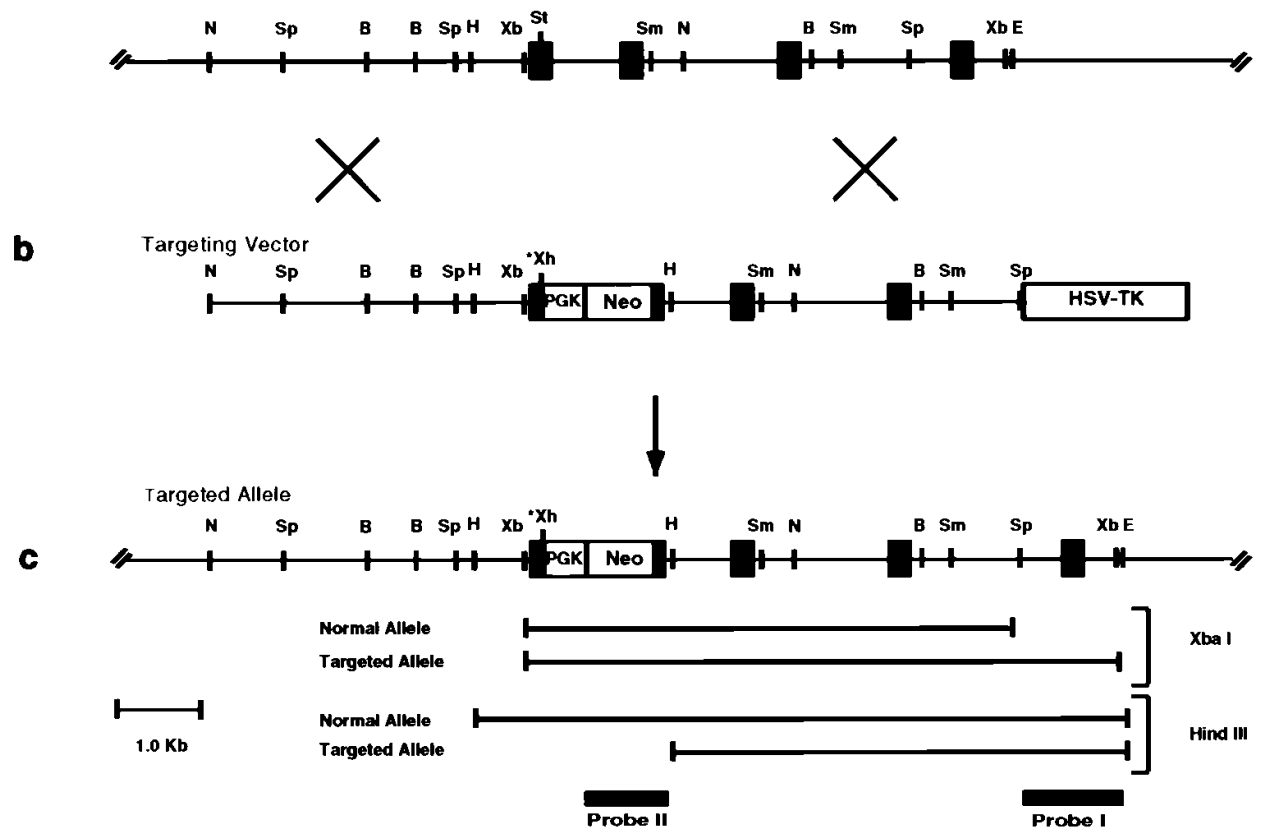

Figure 8. Partial genomic structure of Inpp $5 b$. The genomic locus used for creation of the gene targeting vectors is labeled Normal Allele $(a)$. A polyA $^{-}$neo gene was cloned into the StuI site which had been modified to include a triple frame stop and a XhoI restriction site, and DT-A was inserted to create the targeting vector $(b)$. A homologous recombination event, labeled as Targeted Allele (c), is detected with probe I, which comes from a region $3^{\prime}$ to the targeting construct, and generates different size restriction fragments from the endogenous and recombinant alleles.

shown). These $F_{1}$ mice were then intercrossed and Southern analysis performed on DNA isolated from the tails of the $F_{2}$ mice. 88 mice were analyzed and the distribution of genotypes (29:39:20) did not differ significantly from the expected 1:2:1 Mendelian distribution $\left(\chi^{2}=2.48,1\right.$ degree of freedom, $P>$ $0.10)$.

To study the effect of homologous recombination on Inpp $5 b$ expression, Northern analysis was performed using total RNA isolated from both brains and kidneys of normal and targeted homozygous Inpp $5 b$ mice at 3 wk of age (Fig. 9). Both the 5.0- and 4.4-kb species of Inpp5b mRNA were reduced or absent in kidney, spleen, and liver but were readily detected in the brain of homozygous targeted Inpp $5 b$ mice. To investigate this finding further, RT-PCR was performed across the region of the exon carrying the neomycin cassette insertion using brain, kidney, spleen, and liver mRNA; the PCR product was amplified from equal amounts of total RNA from normal- and homozygous-targeted mice mixed together in one tube. In kidney, brain, and spleen, a markedly reduced amount of a smaller-than-normal RT-PCR product was seen as compared to the normal sized fragment serving as an internal control for amplification (Fig. 10). In contrast, brain RNA showed apparently equal amounts of the normal and smaller RT-PCR products. The RT-PCR products were isolated and sequenced. The smaller fragment was found to be identical to the wild-type cDNA except that it lacked $30 \mathrm{bp}$ of exon downstream from the StuI site into which the synthetic oligonucleotide had been inserted (see Fig. 8). The simplest explanation for this finding is that the insertion of the oligonucleotide containing threeframe stop codons and a XhoI site within the StuI restriction site inadvertently created a consensus $5^{\prime}$ splice site (see Fig. 11). Splicing could then occur between a $3^{\prime}$ splice acceptor site downstream and the artificial $5^{\prime}$ splice site within the oligonucleotide upstream of the PGK-neo cassette, thereby splicing out the neo cassette, the three-frame stop codons, and $30 \mathrm{nu}-$ cleotides within the portion of the exon downstream of the neomycin cassette.

If an mRNA is made in which the alternative splicing occurs, it could possibly be translated to make a protein with a deletion of 10 codons $\left(\operatorname{Inpp} 5 b^{\Delta 10}\right)$. These amino acids are located within one of the highly conserved phospatidylinositol polyphosphate 5-phosphatase domains shared by INPP5B with $O C R L 1$, synaptojanin, and ship (28) and with three synaptojanin-like genes in Saccharomyces cerevisiae that encode enzymes with $\mathrm{PtInsP}_{2}$ 5-phosphatase activity (31). Within these 10 amino acid residues is the very highly conserved pair

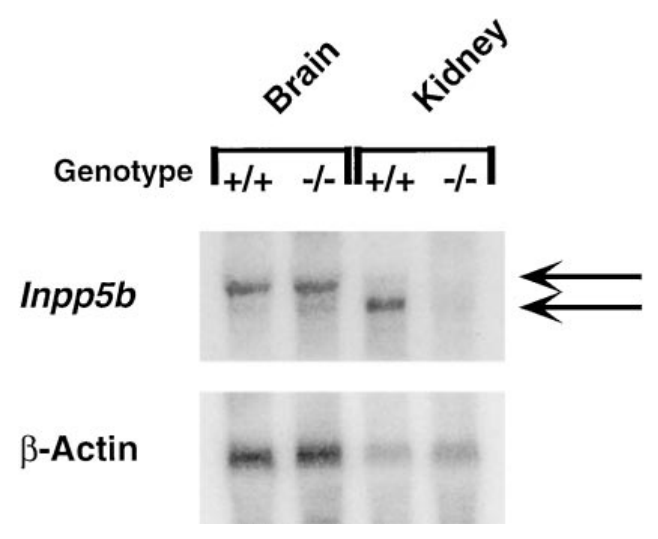

Figure 9. Northern analysis from targeted Inpp $5 b$ mice. RNA was isolated from both brains and kidneys of normal $(+/+)$ and homozygous targeted (-/-) Inpp5b mice and separated on a formaldehyde agarose gel by electrophoresis. The blot was first probed with the Inpp $5 b$ cDNA, stripped, and reprobed with a $\beta$-actin control. The blots were washed to high stringency and exposed to $\mathrm{x}$-ray film at $-70^{\circ} \mathrm{C}$. For Inpp $5 b$, the exposure was for $2 \mathrm{~d}$, and for $\beta$-actin $2 \mathrm{~h}$. The arrows mark the two alternatively spliced forms of Inpp5b. 


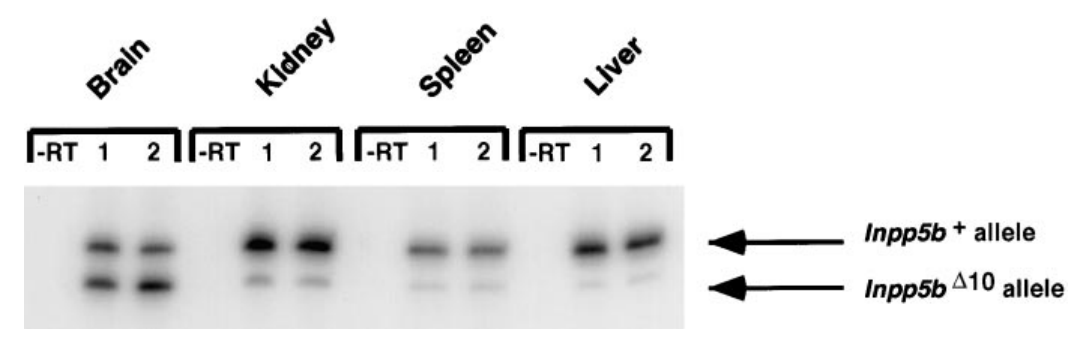

Figure 10. RT-PCR analysis of normal and targeted Inpp $5 b$ mice. In this figure a 1:1 mixture of homozygous normal and homozygous targeted total RNA from four different organs has been mixed, subjected to RT-PCR in the presence of ${ }^{32} \mathrm{P}$-dCTP using primers that flank the insertion site of the neomycin cassette, and the PCR products separated on a $6 \%$ acrylamide gel. Lane 1 contains a 1:1 mixture of RNA from one homozygous normal and one homozygous targeted mouse; lane 2 is a similar 1:1 mixture from two different homozygous normal and homozygous targeted mice. The - RT lane is a control in which RT was omitted from the RT-PCR reaction. The gel was exposed to x-ray film at room temperature for $3 \mathrm{~h}$. As can be seen, both the normal product (Inpp $\left.5 b^{+}\right)$and the product with a 30-bp deletion $\left(\operatorname{Inpp} 5 b^{\Delta 10}\right)$ are amplified in all four tissues. However there is much more of the deleted product in the brain relative to the normal product as compared to the other tissues where it is only present in very small quantities relative to the normal.

of residues, aspartic acid-glutamine, in which a missense mutation in the aspartic acid residue in OCRL1 is known to cause a total loss of enzyme function (28). Thus, it is likely that any protein made would be either highly unstable or enzymatically inactive.

As a direct test of the effect of the disrupted allele on the function of the Inpp5b protein, $\mathrm{PtInsP}_{2}$ 5-phosphatase enzyme assays were performed in cultured mouse fibroblasts under conditions in which the ratio of cetyltriethylammonium bromide to substrate was set at 10:1 and 2.5:1 (Fig. 12). For comparison, cultured fibroblasts from a human patient with Lowe syndrome were assayed under similar conditions. Although total PtInsP $\mathrm{P}_{2}$ 5-phosphatase activity was equal at either detergent substrate ratio in normal fibroblasts, the activity measured at a ratio of 10:1 was markedly deficient in both human and murine fibroblasts carrying mutations in the OCRL1/Ocrl1 gene whereas no difference was seen between normal and OCRL1deficient cells assayed at a 2.5:1 ratio. In contrast, mice homozygous for the targeted Inpp5b allele had normal PtInsP 5-phosphatase activity at a detergent substrate ratio of 10:1 but were markedly deficient at a ratio of $2.5: 1$. We interpret these results as indicating that $(a)$ the enzyme that is the product of the INPP5B/Inpp5b locus is responsible for $>95 \%$ of the PtIns $\mathrm{P}_{2}$ 5-phosphatase activity measured with a detergent substrate ratio of 2.5:1, whereas at a ratio of 10:1, the OCRL1/ Ocrl1 locus is responsible for $>95 \%$ of the $\mathrm{PtInsP}_{2}$ 5-phosphatase activity, and $(b)$ the targeting event has resulted in loss of most or all of Inpp5b function in fibroblasts from mice homozygous for the targeted allele.

Mice homozygous for the targeted Inpp5b allele were viable and fertile when young and showed none of the phenotypic manifestations of Lowe syndrome (Bernard, D., and R.L. Nussbaum, unpublished data). There were no cataracts or abnormalities in growth and development. Urine and serum collection showed no proteinuria and no abnormalities of phosphate or other electrolytes (data not shown). With advancing age, Inpp $5 b$-deficient females remained perfectly healthy; males demonstrated, as their only phenotypic manifestation, a progressive testicular degeneration leading to sterility (Bernard, D., and R.L. Nussbaum, unpublished data). Careful histological examination of Inpp5b-deficient mice at 4 and 12 mo was, otherwise, totally unremarkable. The pathogenesis of the testicular degeneration is the subject of ongoing investigation.
A

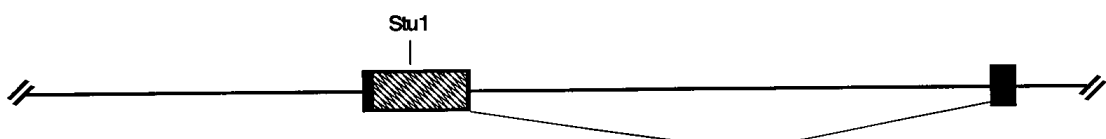

Normal Allele
/ CTA AAA ATC

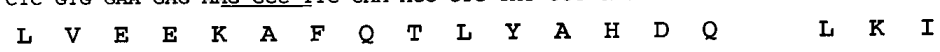

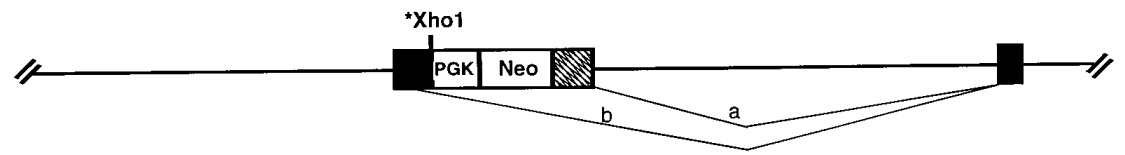

... CTC GTG GAa GAG AAG GTA ATT AGC TGA CTC GAG CCT TCC ...

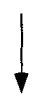

B

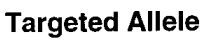
Deletion of 30 basepairs
(10 amino acid residues)
CTC GTG GAA GAG AAG / CTA AAA ATC

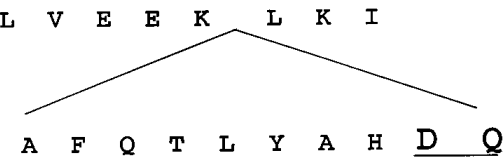

Figure 11. Splicing at the targeted Inpp5b locus. $(A)$ The competition for splicing around the targeted Inpp $5 b$ locus. $a$ shows the normal mechanism of splicing while $b$ shows the competitive splice using the newly formed splice donor caused by insertion of the stop codon-containing oligonucleotide (double underlined) into the Stu1 restriction site (underlined). The box outlines the invariant GT of the newly created splice donor site. The corresponding products are shown at the bottom. (B) The sequence of the smaller RT-PCR product and the resulting smaller $(\Delta 10)$ product with the frame maintained. The vertical arrow represents the exonic junction and shows that the next downstream exon begins in-frame. The $10 \mathrm{de}$ leted amino acids are shown at the bottom, with the highly conserved aspartic acid and glutamine (28) enlarged and underlined. 


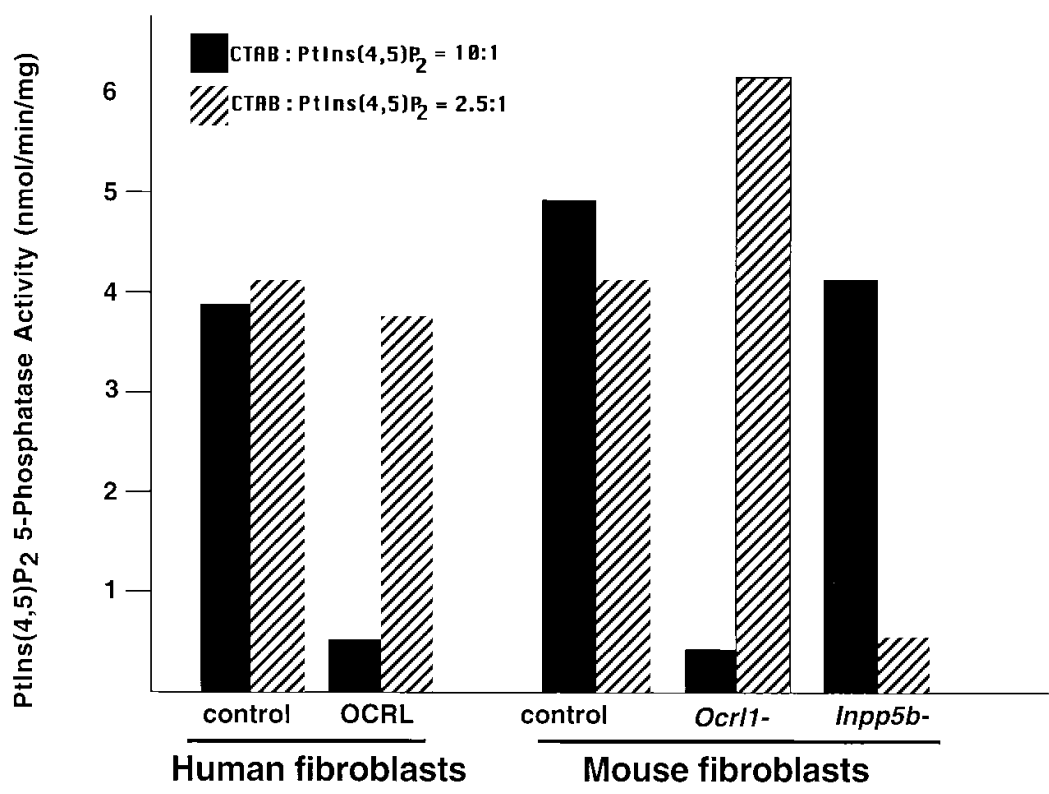

Figure 12. Assays of total PtIns $\mathrm{P}_{2}$ 5-phosphatase activity in cultured mouse embryonic fibroblasts from male mice hemizygous for the deleted Ocrl1 allele $\left(\mathrm{Ocrll}^{-}\right)$or homozygous for the targeted Inpp $5 b$ $\left(\right.$ Inpp $\left.5 b^{-}\right)$at molar ratios of cetyltriethylammonium bromide $(C T A B)$ : PtInsP $P_{2}$ of 10:1 and 2.5:1. For comparison, cultured fibroblasts from a human control individual and a human patient with Lowe syndrome were assayed under similar conditions.
To assess whether Inpp5b could compensate for deficiency of Ocrl1, we sought evidence for functional overlap between the two enzymes by attempting to breed mice deficient in both. As shown in Table I, crosses that would be expected to generate either one in eight or one in four mice deficient in both enzymes failed to generate any liveborn doubly deficient mice $\left(P=1.6 \times 10^{-12}\right.$; exact binomial test $)$. Similar matings were carried out to generate doubly deficient embryos with a frequency of one in four (25\%) and the pregnant mice were killed to allow genotyping of embryos. No doubly deficient embryos were found among 40 normal-looking embryos from seven litters ranging in age from 9.5 to $10.5 \mathrm{dpc}\left(P=10^{-5}\right.$, exact binomial test). In addition to the 40 embryos, there were 14 resorptions in these 7 litters. Assuming the resorptions all represented early implantations that failed to develop, a total of 54 implantations occurred in these 7 litters. The fraction of implantations that failed to develop into embryos (14/54) was $26 \%$, almost precisely what would be expected based on Mendelian inheritance if the double deficiency for Ocrll and Inpp $5 b$ were an embryonic lethal.

\section{Discussion}

There is no explanation for how the characteristic triad of congenital cataracts, mental retardation, and renal tubular dysfunction that occurs in Lowe syndrome arises from a deficiency of a PtIns $\mathrm{P}_{2}$ 5-phosphatase that is widely distributed in human tissues. We therefore attempted to make a mouse

Table I. Outcome of Matings Designed to Produce Mice Deficient in Both Ocrl1 and Inpp5b

\begin{tabular}{lllcc}
\hline $\begin{array}{l}\text { Total } \\
\text { offspring }\end{array}$ & Genotype of offspring & $\begin{array}{c}\text { Expected } \\
\text { frequency }\end{array}$ & $\begin{array}{c}\text { Expected } \\
\text { number }\end{array}$ & $\begin{array}{c}\text { Observed } \\
\text { number }\end{array}$ \\
\hline & & $\%$ & & \\
42 & Inpp $5 b^{-1-} ;$ Ocrl1 $1^{-}$males & 25 & 10.5 & 0 \\
113 & Inpp $5 b^{-1-} ;$ Ocrl1 $1^{-1-}$ females & 12.5 & 14.125 & 0 \\
\hline
\end{tabular}

model for Lowe syndrome to have ready access to tissues affected in the disorder, both prenatally and postnatally, to study how a deficiency of PtIns $\mathrm{P}_{2}$ 5-phosphatase leads to the phenotypic consequences seen in Lowe syndrome. Human OCRL1 and mouse $\mathrm{Ocrl}$ show similar expression patterns in adult tissues, particularly in the organs affected in Lowe syndrome. Prenatally, the occurrence of cataracts as early as 20-24 wk of gestation and the severe neonatal hypotonia seen in Lowe syndrome provide clinical evidence that a deficiency of the enzyme has prenatal consequences in humans. The only direct molecular evidence available that $O C R L 1$ is expressed in human fetal tissue comes from the demonstration of the enzyme in amniocytes and in trophoblast cells obtained from chorionic villus samples (26). In the mouse, expression of Ocrll was readily detectable in ES and in embryos from as early as 9.5 $\mathrm{dpc}$ Thus, there was no indication of a major difference between the species in tissue distribution or timing of expression of OCRL1 and Ocrl1.

Nonetheless, despite successfully creating mice with a complete loss of Ocrl1, none of the phenotypic abnormalities seen in Lowe syndrome were seen in mice lacking the enzyme. One possible exception to the normal phenotype was a statistically significant reduction in their ability to perform on the rotorod test. This finding must be interpreted with caution, however. Although the average for $\mathrm{Ocrl}^{-}$mice was below that of $\mathrm{Ocrl}^{+}$ mice, there was substantial overlap between knockout and control mice in the performance on the rotorod, as many $\mathrm{Ocrl}^{-}$ mice were able to remain on the rod for the full 60 -s test period. The mice were of mixed genetic background $(129 / \mathrm{Sv} / \mathbf{J} \times$ C57BL/6J hybrids) due to the low frequency of germline transmission by the chimeras which prevented us from mating the chimeras directly to $129 / \mathrm{Sv}$ females to make mice with a knockout allele in a pure inbred $129 / \mathrm{Sv}$ background. Whether random genetic background effects could produce this statistically significant difference in rotorod performance between two groups of over 20 mice each is difficult to assess. Instead of expanding the number of animals to average out the background effect, we are carrying out back-crossing experiments designed to place the Ocrll $^{\text {neo }}$ allele in an inbred $129 / \mathrm{Sv}$ background. After eight backcross generations, there appear to be 
no genetic background effects on growth, development, or occurrence of congenital cataracts in male mice carrying an Ocrl1 knockout allele. Future experiments will be performed to reevaluate the complete phenotype in a pure $129 / \mathrm{Sv}$ inbred background.

Why should a deficiency of OCRL1 cause a multisystem disease in humans but not in mice? One possible explanation is that lens, brain, and kidney development and function are different enough between the species that the $O c r l 1$ protein plays little or no role in their development or function in the mouse. Another possible explanation is the existence of a pathway operating in mouse, but not in human, that allows cells and tissues to compensate for loss of Ocrll function by a pathway that circumvents the block. A well documented example of this phenomenon is seen in mice deficient in the $\alpha$ subunit of hexosaminidase A who have histopathological evidence of ganglioside storage but fail to develop full-blown Tay-Sachs disease (32). Unfortunately, the existence of multiple, alternative pathways is hard to address for Ocrll because the metabolic pathways involving phosphoinositides are much more obscure and poorly characterized than is ganglioside catabolism.

There does appear to be one clear difference between mice and humans: there is another enzyme activity that can directly compensate for the deficiency of Ocrl1 in mice but not humans. Several mammalian enzymes are known or suspected (based on amino acid homology) of having PtInsP $\mathrm{P}_{2}$ 5-phosphatase activity in addition to the product of the OCRL1 gene. Of these, the most homologous protein is a 75-kD enzyme with inositol polyphosphate $(16,33)$ and $\mathrm{PtIns}_{2}$ 5-phosphatase (34) activities that is the product of the autosomal INPP5B locus in humans and the Inpp5b locus in mice (35). If compensation by another enzyme activity is responsible for the lack of phenotype in $\mathrm{Ocrll}^{-}$mice, the product of the Inpp5b gene is a prime candidate given its striking amino acid similarity with the Ocrll gene product and their overlapping biochemical activities (9). Such compensation in mice but not in humans could be due to differences between human and mice in expression level, timing, and/or tissue or subcellular distribution of the enzyme. Although there does not appear to be any upregulation of steady-state Inpp5b mRNA in $\mathrm{Ocrl}^{-}$mice as compared to normal littermates (Jänne, P.A., unpublished data), the steady-state levels of human INPP5B mRNA are strikingly reduced, as judged by Northern blot analysis, in many tissues of the adult, including brain and kidney, as compared to mRNA levels of its mouse ortholog, Inpp5b. Hypothetically, the relative increased amount of the Inpp $5 b$ expression in mice could substitute for the function of Ocrll, whereas, perhaps in humans, the INPP5B enzyme is limiting in critical tissues. A significant difference between mice and humans in the timing or distribution of INPP5B and Inpp5b expression during embryonic development could also contribute to the lack of a phenotype in our mice. A comparison of INPP5B and Inpp5b expression has not been carried out in embryonic tissues, but it is known that mouse Inpp5b is expressed in ES and in mouse embryos from $9.5 \mathrm{dpc}$ to late gestation.

In support of the hypothesis of functional overlap of Ocrl1 with Inpp5b, when we crossed mice in an attempt to create strains of mice deficient in both gene products, we failed to find any liveborn mice or even mouse embryos at the 8.5-9.5 dpc stage that lacked the activity of both enzymes. Human $I N P P 5 B$ enzyme is reported to be located in the mitochondria, as opposed to the Golgi complex or the lysosome, in human and monkey cells (36). A strictly mitochondrial localization for mouse Inpp5b activity would need to be reconciled with the functional overlap reported here in the mice. If the two enzymes were strictly located in different subcellular organelles, one might expect that doubly deficient mice would have the same phenotype as mice deficient in Inpp5b alone, i.e., testicular degeneration in males, since the Ocrll-deficient mice have no phenotype. Subcellular localization of mouse Inpp5b is not known and thus it remains possible that not only expression level but also the subcellular localization of the Inpp $5 b$ gene product may be different between mice and humans.

Although mice carrying mutations in the Ocrll gene failed to serve as animal models for the study of the pathogenesis of OCRL, such mice are very useful in two other ways. First, they are already being used to dissect the various biochemical and physiological pathways in which phosphatidylinositol phosphates play important roles, as in the functional overlap of Ocrl1 with Inpp5b. Similar genetic analyses can be applied to other known or suspected phosphatidylinositol 5-phosphatases to clarify their physiological significance and function. Second, from the point of view of clinical medicine, investigation of how $\mathrm{Ocrl1}^{-}$mice escape the sequelae of their enzyme deficiency may suggest metabolic or biochemical interventions that could be useful in preventing or ameliorating the Lowe syndrome in patients.

\section{Acknowledgments}

We thank Jean Richa, Lisa Garret, Cheral Canna, and Theresa Hernandez for their help with making and maintaining the mutant mouse strains and Dr. Gerard Berry for help in serum and urine chemistry measurements. We gratefully acknowledge Dr. Stephen Liebhaber's support and encouragement.

This study was supported by Intramural Research Programs of the National Human Genome Research Institute, the National Institute of Mental Health, and the National Institute of Child Health and Human Development; research grants RO1-HD-23245 (Robert L. Nussbaum) and T32-GM-07170 (Pasi A. Jänne).

\section{References}

1. Lowe, C.U., M. Terrey, and E.A. MacLachan. 1952. Organic aciduria, decreased renal ammonia production, hydrophthalmos, and mental retardation: a clinical entity. Am. J. Dis. Child. 83:164-184.

2. Charnas, L.R., and R.L. Nussbaum. 1994. The oculocerebrorenal syndrome of Lowe (Lowe syndrome). In The Metabolic Basis of Inherited Disease. C.R. Scriver, A.L. Beaudet, W.S. Sly, and D. Valle, editors. McGraw-Hill, New York. 3705-3716.

3. Kenworthy, L., T. Park, and L.R. Charnas. 1993. Cognitive and behavioral profile of the oculocerebrorenal syndrome of Lowe. Am. J. Med. Genet. 46:297-303.

4. Lavin, C.W., and C.A. McKeown. 1993. The oculocerebrorenal syndrome of Lowe. Int. Ophthalmol. Clin. 2:179-191.

5. Reilly, D.S., R.A. Lewis, D.H. Ledbetter, and R.L. Nussbaum. 1988. Tightly linked flanking markers for the Lowe oculocerebrorenal syndrome with application to carrier assessment. Am. J. Hum. Genet. 42:748-755.

6. Kenworthy, L., and L. Charnas. 1995. Evidence for a discrete behavioral phenotype in the oculocerebrorenal syndrome of Lowe. Am. J. Med. Genet. 59: 283-290.

7. Charnas, L.R., and W.A. Gahl. 1991. The oculocerebrorenal syndrome of Lowe. Adv. Pediatr. 31:75-107.

8. Suchy, S.F., I.M. Olivos-Glander, and R.L. Nussbaum. 1995. Lowe Syndrome, a deficiency of a phosphatidylinositol 4,5-bisphosphate 5-phosphatase in the Golgi apparatus. Hum. Mol. Genet. 4:2245-2250.

9. Zhang, X., A.B. Jefferson, V. Auethavekiat, and P.W. Majerus. 1995. The protein deficient in Lowe syndrome is a phosphatidylinositol-4,5-bisphosphate 5-phosphatase. Proc. Natl. Acad. Sci. USA. 92:4853-4856.

10. Olivos-Glander, I.M., P.A. Jänne, and R.L. Nussbaum. 1995. The oculocerebrorenal syndrome gene product is a $105-\mathrm{kD}$ protein localized to the Golgi 
complex. Am. J. Hum. Genet. 57:817-823.

11. Zhang, X., P.A. Hartz, E. Philip, L.C. Racusen, and P.W. Majerus. 1998. Cell lines from kidney proximal tubules of a patient with Lowe syndrome lack OCRL inositol polyphosphate 5-phosphatase and accumulate phosphatidylinositol 4,5-bisphosphate. J. Biol. Chem. 273:1574-1582.

12. Capecchi, M. 1989. Altering the genome by homologous recombination. Science. 244:1288-1292.

13. Smithies, O. 1993. Animal models of human genetic diseases. Trends Genet. 9:112-116.

14. Sambrook, J., E.F. Fritsch, and T. Maniatis. 1989. Molecular Cloning: A Laboratory Manual. Cold Spring Harbor Laboratory Press, Cold Spring Harbor, NY. 545 pp.

15. Leahey, A.M., L.R. Charnas, and R.L. Nussbaum. 1993. Nonsense mutations in the OCRL-1 gene in patients with the oculocerebrorenal syndrome of Lowe. Hum. Mol. Genet. 4:461-463.

16. Ross, T.S., A.B. Jefferson, C.A. Mitchell, and P.W. Majerus. 1991. Cloning and expression of human 75-kDa inositol polyphosphate-5-phosphatase. $J$. Biol. Chem. 266:20283-20289.

17. Attree, O., I.M. Olivos, I. Okabe, L.C. Bailey, D.L. Nelson, R.A. Lewis, R.R. McInnes, and R.L. Nussbaum. 1992. The Lowe oculocerebrorenal syndrome gene encodes a novel protein highly homologous to inositol polyphosphate-5-phosphatase. Nature. 358:239-242.

18. Harlow, E., and D. Lane. 1988. Antibodies: A Laboratory Manual. Cold Spring Harbor Laboratory Press, Cold Spring Harbor, NY. 726 pp.

19. Joyner, A.L. 1993. Gene Targeting: A Practical Approach. IRL Press, Oxford

20. McCarrick, J.W., III, J.R. Parnes, R.H. Seong, D. Solter, and B.B. Knowles. 1993. Positive-negative selectin gene targeting with the diphtheria toxin A-chain gene in mouse embryonic stem cells. Transgenic Res. 2:183-190.

21. Ho, S.N., H.D. Hunt, R.M. Horton, J.K. Pullen, and L.R. Pease. 1989. Site-directed mutagenesis by overlap extension using the polymerase chain reaction. Gene. 77:51-59.

22. Robertson, E.J. 1987. Embryo-derived stem cell lines. In Teratocarcinomas and Embryonic Stem Cells: A Practical Approach. E.J. Robertson, editor. IRL Press, Oxford. 71-112.

23. Lei, H., S.P. Oh, M. Okano, R. Juttermann, K.A. Goss, R. Jaenisch, and E. Li. 1996. De novo DNA cytosine methyltransferase activities in mouse embryonic stem cells. Development. 122:3195-3205.

24. Deng, C., A. Wynshaw-Boris, F. Zhou, A. Kuo, and P. Leder. 1996. Fibroblast growth factor receptor 3 is a negative regulator of bone growth. Cell. 84:911-921.

25. Yamanaka, S., M.D. Johnson, A. Grinberg, H. Westphal, J.N. Crawley,
M. Taniike, K. Suzuki, and R.L. Proia. 1997. Targeted disruption of the hexa gene results in mice with biochemical and pathological features of Tay-Sachs disease. Proc. Natl. Acad. Sci. USA. 91:9975-9979.

26. Suchy, S.F., and R.L. Nussbaum. 1997. Lowe oculocerebrorenal syndrome (update). In The Metabolic and Molecular Bases of Inherited Disease (CD-ROM Update). C.R. Scriver, A.L. Beaudet, W.S. Sly, and D. Valle, editors. McGraw-Hill, New York.

27. Nussbaum, R.L., B.M. Orrison, P.A. Janne, L. Charnas, and A.C. Chinault. 1997. Physical mapping and genomic structure of the Lowe syndrome gene OCRL1. Hum. Genet. 99:145-150.

28. Lin, T., B.M. Orrison, A.M. Leahey, S.F. Suchy, D.J. Bernard, R.A. Lewis, and R.L. Nussbaum. 1997. Spectrum of mutations in the OCRL1 gene in the oculocerebrorenal syndrome. Am. J. Hum. Genet. 60:1384-1388.

29. Donehower, L.A., M. Harvey, B.L. Slagle, M.J. McArthur, C.A. Montgomery, Jr., J.S. Butel, and A. Bradley. 1992. Mice deficient for p53 are developmentally normal but susceptible to spontaneous tumors. Nature. 356:215-221.

30. Lin, T., B.M. Orrison, S.F. Suchy, R.A. Lewis, and R.L. Nussbaum. 1998. Mutations are not uniformly distributed throughout the OCRL1 gene in Lowe syndrome patients. Mol. Genet. Metab. In press.

31. Srinivasan, S., M. Seaman, Y. Nemoto, L. Daniell, S. Emr, P. DeCamilli, and R.L. Nussbaum. 1997. Disruption of three phosphatidylinositol polyphosphate 5-phosphatase genes from $S$. cerevisiae results in pleiotropic abnormalities of vacuole morphology, cell shape, and osmohomeostasis. Eur. J. Cell Biol. $74: 350-360$.

32. Sango, K., S. Yamanaka, A. Hoffman, Y. Okuda, A. Grinberg, H. Westphal, M.P. McDonald, J.N. Crawley, K. Sandhoff, K. Suzuki, and R.L. Proia. 1995. Mouse models of Tay-Sachs and Sandhoff diseases differ in neurologic phenotype and ganglioside metabolism. Nat. Genet. 11:170-176.

33. Mitchell, C.A., T.M. Connolly, and P.W. Majerus. 1989. Identification and isolation of a 75-kDa inositol polyphosphate-5-phosphatase from human platelets. J. Biol. Chem. 264:8873-8877.

34. Matzaris, M., S.P. Jackson, K.M. Laxminarayan, C.J. Speed, and C.A. Mitchell. 1994. Identification and characterization of the phosphatidylinositol(4,5)-bisphosphate 5-phosphatase in human platelets. J. Biol. Chem. 269:33973402

35. Jänne, P.A., J.M. Rochelle, P.A. Martin-DeLeon, D. Stambolian, M.F Seldin, and R.L. Nussbaum. 1995. Mapping of the 75-kDa inositol polyphosphate-5-phosphatase (Inpp5b) to distal mouse chromosome 4 and its exclusion as a candidate gene for dysgenetic lens. Genomics. 28:280-285.

36. Speed, C.J., M. Matzaris, P.I. Bird, and C.A. Mitchell. 1995. Tissue distribution and intracellular localisation of the $75-\mathrm{kDa}$ inositol polyphosphate 5-phosphatase. Eur. J. Biochem. 234:216-224. 